\title{
Postnatal pituitary and follicular activation: a revisited hypothesis in a sheep model
}

\author{
Laura Torres-Rovira, Sara Succu, Valeria Pasciu, Maria Elena Manca, Antonio Gonzalez-Bulnes ${ }^{1}$, \\ Giovanni Giuseppe Leoni, Maria Grazia Pennino², Antonio Spezzigu ${ }^{3}$, Marilia Gallus ${ }^{4}$, \\ Maria Dattena ${ }^{4}$, Danielle Monniaux ${ }^{5,6,7,8}$, Salvatore Naitana and Fiammetta Berlinguer
}

Department of Veterinary Medicine, University of Sassari, Via Vienna 2, 07100 Sassari, Italy, ${ }^{1}$ Department of Animal Reproduction, INIA, Avenida Puerta de Hierro s/n, 28040 Madrid, Spain, ${ }^{2}$ Depto. de Botânica, Ecologia e Zoologia - DBEZ, Universidade Federal do Rio Grande do Norte - UFRN, Campus Universitário s/n, Lagoa Nova. Cx postal 1524. CEP 59.098-970 Natal (RN), Brazil, ${ }^{3}$ Embryo Sardegna, Technology, Reproduction, and Fertility, Perfugas, Sassari, Italy, ${ }^{4}$ AGRIS Sardegna, Department of Animal Production, Loc. Bonassai, 07100 Sassari, Italy, ${ }^{5}$ INRA, UMR85 Physiologie de la Reproduction et des Comportements, F-37380 Nouzilly, France, ${ }^{6}$ CNRS, UMR7247 Physiologie de la Reproduction et des Comportements, F-37380 Nouzilly, France, ${ }^{7}$ Université François Rabelais de Tours, F-37041 Tours, France and ${ }^{8}$ IFCE, F-37380 Nouzilly, France

Correspondence should be addressed to F Berlinguer; Email: berling@uniss.it

\begin{abstract}
The importance of postnatal pituitary activation as regards female reproductive development is not yet understood. By taking advantage of the experimental model developed in a previous study, i.e. ewe lambs expressing markedly different ovarian phenotypes at 50 days of age, we designed this study to determine whether differences found in ovarian status during the early prepubertal period are due to different patterns of postnatal pituitary activation, and to assess whether these differences have long lasting effects on subsequent reproductive performance. Results showed that ewe lambs with high antral follicle count (AFC) at 50 days of age had significantly lower plasma FSH concentrations and higher anti-Mullerian hormone (AMH) concentrations during the first 9 weeks of age compared with low AFC ewe lambs $(P<0.0001)$. With a longitudinal experiment we showed that a high AFC in the early prepubertal period is associated with consistently higher AMH concentrations and numbers of antral follicles up to the postpubertal period, and with higher pregnancy rates in the first breeding season. In addition, the effect of age in decreasing AMH concentrations was more marked in the low AFC group. Results of the present study demonstrate that ewe lambs undergo different patterns of postnatal pituitary activation. A high AFC at 50 days of age indicates an advanced phase of ovarian maturation, which was accompanied by constantly higher AMH concentrations up to the postpubertal period, a greater ovarian response to FSH stimulation and by higher pregnancy rates at first mating, as compared with the low AFC group.
\end{abstract}

Reproduction (2016) 151 215-225

\section{Introduction}

The reproductive axis and its hormonal control systems are largely established in fetal life, thus the in utero environmental conditions influence their programming and consequently the phenotype expressed later in life (Zambrano et al. 2014). However, according to the perinatal programming theory, early postnatal conditions also have long-lasting physiological effects (Gluckman et al. 2008), and recent studies evidenced that they can influence the newborn's future reproductive performance (Sloboda et al. 2009).

The first months of life provide a window of opportunity to examine the function of the hypothalamic-pituitary-gonadal (HPG) axis before puberty (Kuiri-Hänninen et al. 2014). Babies born small for gestational age have decreased ovarian volume, reduced ovulation rate and increased follicle stimulating hormone ( $\mathrm{FSH}$ ) concentrations when reaching puberty denoting that prenatal growth has endocrine effects that affects reproduction later in life (Chellakooty et al. 2003). In the context of the perinatal programming theory, this period might be important for further reproductive health and disease and therefore our group proposes a sheep model to the study of this relevant period and its later consequences.

During the first postnatal months an important phase in normal reproductive development takes place. 
The HPG axis is transiently activated, and elevated concentrations of gonadotropins are produced (Forest et al. 1980, Schmidt \& Schwarz 2000, Kuiri-Hänninen et al. 2011a,b) in a phenomenon referred to as 'minipuberty'. These hormonal changes are probably triggered by the decline after birth in sex steroidmediated inhibition of gonadotropin secretion exerted by maternal placental and gonadal steroids (Lee 2003). In infant boys, the postnatal pituitary activation is associated with testicular testosterone secretion, penile and testicular growth, and an increase in the number of Sertoli and germ cells (Kuiri-Hänninen et al. 2011a), and this period is therefore considered to be an important phase in reproductive development in males. In infant girls even though reproductive hormones, especially FSH, exhibit large variations between diverse individuals (Chellakooty et al. 2003), circulating FSH concentration transiently increase during postnatal pituitary activation (Beck-Peccoz et al. 1991, Kuiri-Hänninen et al. 2011b) reaching concentrations similar to those observed in periovulatory women. Anti-Mullerian hormone (AMH) concentrations also increase, peaking a few months after birth (Hagen et al. 2010). A similar situation has been seen in cattle suggesting that the heightening in the follicular recruitment was produced by the remarkable increase in $\mathrm{FSH}$ concentration that occurs early after birth, then later falls due to an increase in the secretion of steroid and inhibin from the numerous antral follicles that have grown during the previous weeks (Rawlings et al. 2003, reviewed by Hernandez-Medrano et al. (2012)). Likewise, high plasma FSH concentrations have been observed also in ewe lambs in the first 2 months of life (Savoie et al. 1979, McNatty et al. 1998, Mahdi \& Khallili 2008). However, the possible importance of this activation as regards female reproductive development is not yet understood.

It is assumed that AMH has some role in folliculogenesis (Gruijters et al. 2003). AMH is produced in granulosa cells of developmentally advanced growing follicles, preantral, and small antral follicles (Weenen et al. 2004), and declines at the time of follicle selection (Jeppesen et al. 2013). In adult ewes, AMH controls the rate at which follicles progress to the gonadotropindependent stage from the gonadotropin-responsive stage (Campbell et al. 2012). FSH may play a role in the down-regulation of $\mathrm{AMH}$ expression when small antral follicles differentiate into large antral follicles (Baarends et al. 1995) with numerous studies reporting a negative correlation between concentrations of FSH and AMH (Fanchin et al. 2003, Silberstein et al. 2006) with decreased $\mathrm{AMH}$ production when high FSH levels are present (Rico et al. 2011, reviewed by Monniaux et al. (2013)). The effect of AMH over follicles sensitivity to FSH is contradictory. For some authors AMH seems to inhibit follicles sensitivity to FSH (Pellatt et al. 2011), while other authors point that $\mathrm{AMH}$ enhances the effect of FSH (McGee et al. 2001).
Despite the advanced knowledge in adult physiology, many unknowns regarding the link between $\mathrm{AMH}$, follicular development, and FSH in the early prepubertal period need to be elucidated.

In a previous study in ewe lambs (Torres-Rovira et al. 2014) we described significant inter-individual differences in antral follicle count (AFC) in the early prepubertal period. These differences were linked to differences in circulating AMH concentrations, follicular response to exogenous $\mathrm{FSH}$ administration, and oocyte quality. On the other hand, and in contrast to major findings in adult ovaries, AFC was not predictive of differences in either the number of healthy follicles or the size of the primordial follicle pool in prepubertal ovaries. We speculated that during the early prepubertal period follicular recruitment and development reflect the changes in the endocrine milieu and are preparatory to the subsequent development of the reproductive function.

As the early postnatal development of antral follicles could be linked to FSH stimulation, we hypothesize that the observed inter-individual differences in ovarian phenotype and function in the early prepubertal period might be related to differences in the pattern of postnatal pituitary activation. In our opinion, sheep is a suitable animal model for the study of the 'minipuberty' phenomenon with a lower cost, shorter gestation length and faster development than larger animals and superior developmental similarities to humans in terms of prenatal programming and developmental stages than the usual rodent model. Thus, the present study was carried out to determine if differences found in ovarian status during the early prepubertal period are due to different patterns of postnatal pituitary activation, and to assess whether these differences have long lasting effects on the subsequent reproductive performance. To achieve these objectives, we took advantage of the experimental model developed in a previous study, i.e. ewe lambs expressing markedly different ovarian phenotypes at 50 days of age (TorresRovira et al. 2014). In the present study we studied pituitary (FSH concentrations) and ovarian (AMH concentrations) function during the first weeks after birthin ewe lambs with a high ( $\geq 30$ follicles) and a low ( $\leq 15$ follicles) AFC at 50 days of age. Then, to determine eventual long lasting effects, in the same experimental model we assessed the response to the exogenous FSH ovarian reserve test (EFORT) at 50, 195 (6.5 months - peripubertal) and 496 days of age (16.5 months postpubertal). Finally, we assessed pregnancy rates at first breeding season.

\section{Materials and methods}

The experimental procedures with animals (sheep, Ovis aries) were approved by the Animal Care and Use Committee of the University of Sassari, Italy. All experimental procedures were carried out at the experimental facilities of the Department of 
Animal Production, AGRIS Sardegna, Bonassai, Sassari, Italy (latitude: $40^{\circ} 40^{\prime} 26^{\prime \prime}$ - longitude: $\left.8^{\circ} 22^{\prime} 1^{\prime \prime}\right)$. These facilities meet the requirements of the European Union for Scientific Procedure Establishments. The experimental procedures followed ethical guidelines for care and use of agricultural animals for research (EC Directive 86/609/EEC for animal experiments). All the animals used were Sarda ewes and lambs housed outdoors with indoor access, and fed with a live-weight maintenance ration.

All reagents and media were from Sigma Chemical Co. unless otherwise specified.

\section{Study 1. Pituitary and ovarian function during the postnatal period in ewe lambs with high and low AFC}

This study was conducted to assess whether the expression of different ovarian phenotypes in the early prepubertal period is linked to differences in the pattern of postnatal pituitary activation in ewe lambs. Blood samples from December 2012/January 2013 born Sarda ewe lambs $(n=146)$ were taken weekly from the week of birth until 9 weeks of age with vacuum blood evacuation tubes containing Lithium Heparin (Vacutainer Systems Europe, Becton Dickinson, Meylan Cedex, France). Immediately after recovery, blood samples were centrifuged at $1500 \mathrm{~g}$ for $10 \mathrm{~min}$ at $4{ }^{\circ} \mathrm{C}$ and plasma was removed and stored at $-20{ }^{\circ} \mathrm{C}$. At 6 weeks old ewe lambs were classified by transrectal ultrasonography according to the number of $\geq 2 \mathrm{~mm}$ follicles in the ovaries and assigned into two experimental groups: high AFC ( $\geq 30$ follicles) and low AFC ( $\leq 15$ follicle), as described in a previous study (TorresRovira et al. 2014). Plasma samples from 50 ewe lambs in the categories high AFC $(n=25)$ and low AFC $(n=25)$ were analyzed to study circulating hormone concentrations $(\mathrm{AMH}$ and $\mathrm{FSH}$ ) from birth to 9 weeks of age.

\section{Hormone analyses}

To measure FSH concentrations the FSH (sheep) ELISA kit (Abnova, Neihu District, Taipei City, Taiwan), specific for sheep $\mathrm{FSH}$, was used following the manufacturer instructions in an automatic ELISA analyzer (Personal LAB, Adaltis, Italy). The intra- and inter-assay coefficients of variability were $<15 \%$ for both.

$\mathrm{AMH}$ concentration was measured in sheep plasma by using the AMH Gen II ELISA kit (Beckman Coulter, Inc., Brea, CA, USA) as previously described (Lahoz et al. 2012, Estienne et al. 2015). AMH concentrations were determined in $50 \mu \mathrm{l}$ aliquots of undiluted plasma. The sensitivity (limit of detection) of the assay was $0.08 \mathrm{ng} / \mathrm{ml}$, while the inter- and intra-assay variation coefficients were 5.6 and $5.4 \%$ respectively. For AMH assay in samples recovered during the EFORT tests, EDTA $(1.8 \mathrm{mg} / \mathrm{ml}$, final concentration) was added to plasma samples and to the standards before assay, thus allowing an improvement of the sensitivity of the assay to $0.02 \mathrm{ng} / \mathrm{ml}$ (Rico et al. 2012). The AMH concentration given to animals when $\mathrm{AMH}$ was not detectable was assay's limit of detection, $0.02 \mathrm{ng} / \mathrm{ml}$. Study 2. Responsiveness of follicular population to the
exogenous EFORT in the pre and postpubertal period

Forty eight Sarda ewe lambs from the same flock, with a mean age of $49.77 \pm 1.15$ day-old (born in December-January) and a mean body weight of $11.82 \pm 0.34 \mathrm{~kg}$ at the beginning of the study, were selected according to their ovarian phenotype (low AFC, $n=24$; high AFC, $n=24$ ) determined by characterizing the AFC by transrectal ultrasonography as described in a previous study (Torres-Rovira et al. 2014). Animals were maintained together under the same conditions and diet throughout the experimental procedure, being housed outdoors with indoor access. Age and birth weight, were analyzed to confirm that there were no significant differences that may justify per se different ovarian phenotypes. Initial weight, when ewe lambs were classified into the two experimental groups, and peripubertal weight were also recorded.

The EFORT test (Fanchin et al. 1994, Kwee et al. 2006) was made before puberty at an early prepubertal age (50 days of age), at a peripubertal age (195 days of age) since Sarda sheep usually reach puberty at 7-8 months of age (Carcangiu et al. 2005) and at a postpubertal age (496 days of age) during nonbreeding season for this breed and latitude. Briefly, on Day 0 the AFC was determined by transrectal ultrasonography, with a real-time B-mode scanner (Aloka SSD 500, Aloka Co., Tokyo, Japan) fitted with a $7.5 \mathrm{MHz}$ linear-array probe appropriate to the size of the animal (rigid laparoscopic transducer UST5526L-7.5, Aloka Co. at 50 days of age and $82 \mathrm{~mm}$ prostate transducer UST-660-7.5, Aloka Co. at 195 and 496 days of age). Ultrasounds were carried out as previously described and validated (Gonzalez-Bulnes et al. 1994). The number of follicles for each category (total, 2, 3 and $\geq 4 \mathrm{~mm}$ in diameter) was written down. Afterwards, one-shot intramuscular dose of $105 \mathrm{IU}$ of porcine FSH (Folltropin, Bioniche Animal Health, Minitublbérica, S.L., Reus, Spain) was administered. In order to accommodate to the larger size of the animals, for the EFORT performed after puberty (496 days of age), the intramuscular FSH dose was increased to $175 \mathrm{IU}$. Twenty-four hours later (Day 1), the growth of the antral follicles was assessed by a second ultrasonographic scanning of the ovaries. The response to ovarian stimulation was evaluated by the difference in the number of follicles between Day 1 and 0 for each follicular category, understood as the number of new follicles. The assessment of AFC has inter-observer and intra-observer variations (Jayaprakasan et al. 2008), for that reason in order to minimize the operator-dependent variability the same expert operator performed the ultrasonographic scanning in the three EFORTs.

Blood samples were drawn with vacuum blood evacuation tubes containing lithium heparin (Vacutainer Systems Europe) on Day 0 and Day 1 . Immediately after recovery, blood samples were centrifuged at $1500 \mathrm{~g}$ for $15 \mathrm{~min}$ at $4{ }^{\circ} \mathrm{C}$ and plasma was removed and stored at $-20{ }^{\circ} \mathrm{C}$ until assayed for $\mathrm{AMH}$ determination, as described in Study 1.

For the EFORT test performed after puberty (496 days of age), the number of animals was reduced to nine animals in the high AFC group and 15 animals in the low AFC group because only animals that did not delivered were used due of the impossibility of hormonal injection in lactating animals. 


\section{Study 3. Reproductive function in adulthood}

This study was conducted to determine if the differences in plasma AFC and AMH concentrations seen at an early prepubertal age in Sarda ewe lambs with high or low AFC would entail differences in pregnancy rate at first breeding season. Animals from Study 2 were used in the current experiment. Two ewes from the low AFC group died and two more (one from each AFC group) were momentarily excluded from the experiment at first breeding season due to health problems, thus, pregnancy rate at first breeding season was assessed in 44 ewes $(n=23$ high AFC group, $n=21$ low AFC group).

Following the usual reproductive practices for ewe lambs that will replace the base sheep population of the centre (Department of Animal Production, AGRIS Sardegna), rams were introduced into the ewe flock from August to the end of September. Twenty days after the removal of the rams from the flock, pregnancy diagnosis was performed using transrectal ultrasonography (Aloka SSD 500, fitted to $82 \mathrm{~mm}$ prostate transducer UST-660-7.5, Aloka Co.). Pregnant sheep displayed enlargement of the uterine horns, embryo heartbeat was evidenced and in more advanced stages of pregnancy placentomes were seen.

\section{Statistical analyses}

Statistical analysis was performed using the statistical software program Statgraphic Centurion XV (Version 15.2.06 for Windows; StatPoint, Inc., Herndon, VA, USA) and a probability of $P<0.05$ was considered to be the minimum level of significance. Results are expressed as mean \pm S.E.M.

\section{Study 1}

Differences between high and low AFC groups in birth weight were determined by ANOVA. Differences in plasma AMH and FSH concentrations between the two experimental groups were assessed by general linear model (GLM) where: $Y=\mu+$ week of age + group + week of age $\times$ group + ewe lambs. Age and group were considered fixed factors and ewe lambs a random factor. The method used to discriminate between the means was Fisher's least-significant-difference (I.s.d.) procedure. The probabilities obtained by the I.s.d. test were corrected by Bonferroni's correction for multiple comparisons. Possible correlations between plasma $\mathrm{AMH}$ and FSH concentrations were determined.

\section{Study 2}

Differences between high and low AFC groups in age and weight at the beginning of the study, birth and peripubertal weight were determined by ANOVA. Differences in follicle numbers and $\mathrm{AMH}$ concentrations at different ages, between the two experimental groups, and between Days 0 and 1 of treatment, were assessed by GLM. The method used to discriminate between the means was Fisher's I.s.d. procedure. The probabilities obtained by the I.s.d. test were corrected by Bonferroni's correction for multiple comparisons.
In addition, we used Generalized Linear Mixed Models (GLMMs) to analyze which factors influence the $\mathrm{AMH}$ concentration variability. Specifically, the expected values of $\mathrm{AMH}$ in each measure were related to independent variables, namely age of the individual, the group, and the day of treatment. The remaining potential source of variation on the $\mathrm{AMH}$ values could be due to the individual-specific differences in treatment. The specific individual behaviour caused by random aspects could have caused some of the variation in the data. Ignoring such non-independence of the data may lead to an invalid statistical inference. To remove any bias caused by individual-specific differences in the sample, a random effect was included in the model.

Except for the variable 'age of the individual', which is continuous, the other explanatory variables are all categorical: number of days of treatment $\left({ }^{\prime} 0\right.$ ' and ' 1 ') and group ('high AFC' and 'low AFC').

Effects of categorical variables are considered for k-1 of the $k$ factor levels, with the remaining one being considered as the base level. Hence the estimated coefficient of each factor level will indicate the deviation with respect to the value of the base level.

The fixed effects quantify the overall effects of factors on AHM concentrations; the random effects quantify the variation across individuals of the fixed-effect parameters.

To fit GLMMs we used the 'Ime4' library of the R-software (RC Team 2014).

All the resulting models obtained from combining the mentioned variables and the respective interactions were fitted and compared. The Akaike information criterion (AIC) (Akaike 1974) was used as a measure for the goodness-of-fit. The smaller the AIC, the better the compromise between fit and parsimony.

\section{Study 3}

The $\chi^{2}$-test was used to determine differences in pregnancy rates at the first breeding season between high and low AFC groups.

\section{Results}

Study 1. Pituitary and ovarian function during the first weeks after birth in ewe lambs with high and low AFC

In the first week of age, $\mathrm{AMH}$ was detected in the $48 \%$ of the ewe lambs (12/25) from the high AFC group, while it was under the limit of detection for all ewe lambs from the low AFC group (25/25). At 4 weeks of age, AMH plasma concentrations from all ewe lambs from the high AFC group could be detected, while, for the low AFC group, the detection of $\mathrm{AMH}$ concentrations in all animals could not be reached until the 9th week.

Circulating $\mathrm{FSH}$ and $\mathrm{AMH}$ concentrations proved to be negatively correlated during the first 9 weeks of age in ewe lambs ( $P<0.001$, correlation coefficient: -0.184$)$. During this period, mean plasma FSH concentrations were significantly higher in the low compared with the high AFC group, while the opposite was found for 
plasma $\mathrm{AMH}$ concentrations, being higher in the high compared with the low AFC group $(P<0.0001$, Fig. 1$)$. In addition, being an interaction between groups and age $(P<0.0001)$, FSH and AMH surge patterns differed significantly between the two experimental groups.

In ewe lambs with high AFC, the postnatal FSH surge was barely detected, as its concentrations reached values higher than those recorded at birth in the 2nd week of age $(P<0.01)$, and then remained relatively stable up until the 9th week of age (Fig. 1). On the other hand, in ewe lambs with low AFC, circulating FSH concentrations increased sharply soon after birth, peaked between the 2 nd and 5th weeks of age, and then declined gradually until the 9th week of age $(P<0.01)$.

Regarding the trend of $\mathrm{AMH}$ concentrations during the study, in the low AFC group, although values progressively increased, this elevation was not significant in the first 9 weeks of age. However, in the high AFC group, there was a marked increase in $\mathrm{AMH}$ plasma concentrations that peaked in the 5 th week of age $(1.065 \pm 0.095 \mathrm{ng} / \mathrm{ml})$ to decline gradually from the 6th week $(P<0.001$, Fig. 1$)$.

\section{Study 2. Responsiveness of follicular population to the exogenous EFORT in the pre and postpubertal period}

There were no significant difference between animals from the high and low AFC groups either in the mean age (49.56 \pm 1.72 day-old and $49.96 \pm 1.55$ day-old, for high AFC vs low AFC) and weight $(12.38 \pm 0.43 \mathrm{~kg}$ and $11.27 \pm 0.51 \mathrm{~kg}$, for high AFC vs low AFC) at the beginning of the study, or in the mean birth weight $(3.58 \pm 0.15 \mathrm{~kg}$ and $3.45 \pm 0.10 \mathrm{~kg}$, for high AFC vs low AFC) or peripubertal weight $(27.73 \pm 0.80 \mathrm{~kg}$ and $26.21 \pm 1.00 \mathrm{~kg}$, for high AFC vs low AFC) that could per se justify differences in the response to the EFORT.
The EFORTs performed in the peripubertal and postpubertal periods showed that the differences in the ovarian phenotypes observed in the early prepubertal period ( 50 days of age) between the high and low AFC groups, although less marked, were maintained at least during the first 16 months of age (Fig. 2). In the peripubertal period (195 days of age), although the number of total follicles ( $\geq 2 \mathrm{~mm}$ ) did not differ between the two experimental groups at Day 0, follicular response to $\mathrm{FSH}$ administration was higher in the high AFC group compared with the low group. This difference was mainly due to a higher number of $2 \mathrm{~mm}$ follicles $(P<0.0001)$. In the postpubertal period (496 days of age), the high AFC groups still showed a higher number of total follicles, both before and after FSH administration $(P<0.0001)$. Differences in the follicular population were accompanied by differences in the circulating concentration of $\mathrm{AMH}$. At every time point analyzed, its values were always higher in the high AFC group compared with the low group, both before and after FSH administration $(P<0.0001)$.

It should be pointed out that in the early prepubertal period the follicular population before FSH administration differed significantly in most follicular categories to that found in the peripubertal and postpubertal periods for both groups (Fig. 2). However, while in the high AFC group the total number of follicles observed at 50 days of age was drastically reduced at 195 and 496 days of age, mainly due to the decrease in the most abundant follicular category ( $2 \mathrm{~mm}$ follicles), in the low AFC group the opposite trend was seen, with an increase in the number of total follicles at 195 and 496 days of age compared with 50 days of age (Fig. 2). In both groups, follicles $\geq 4 \mathrm{~mm}$ in diameter increased with age $(P<0.0001)$. In both groups, circulating AMH concentrations dropped from the early prepubertal to the
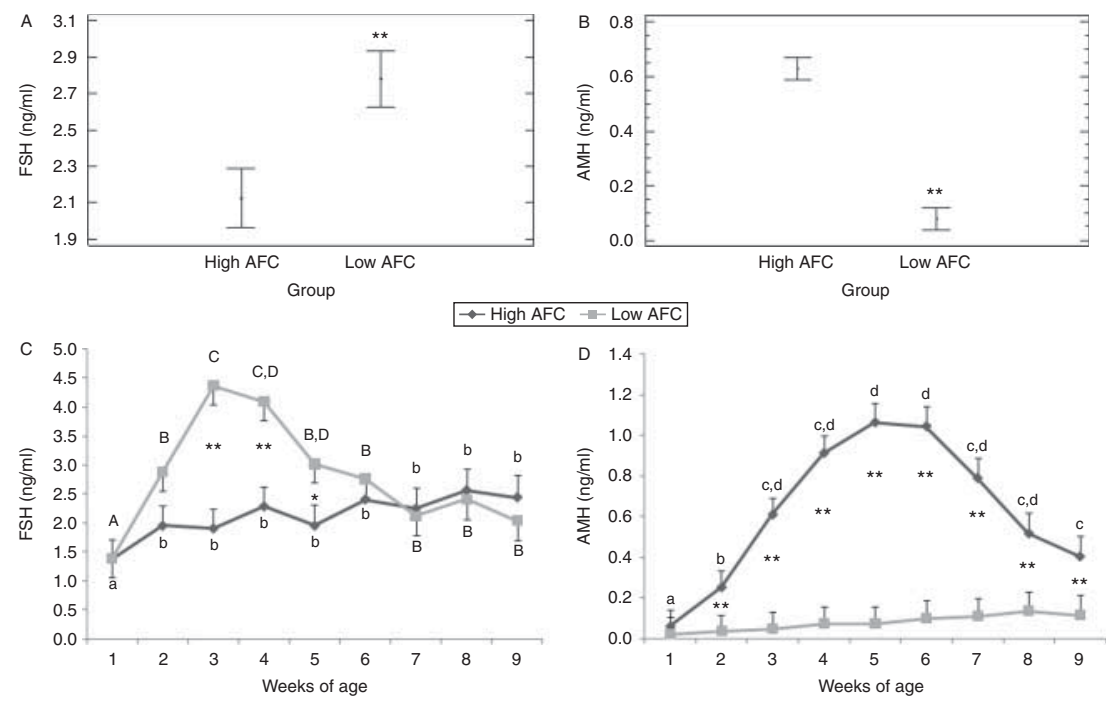

Figure 1 Differences in $\mathrm{FSH}$ ( $\mathrm{A}$ and $\mathrm{C}$ ) and $\mathrm{AMH}$ plasma levels ( $B$ and $D$ ) during the first 9 weeks of age in ewe lambs assigned to high AFC $(\geq 30$ follicles, $n=25$ ) or low AFC group ( $\leq 15$ follicles, $n=25$ ) according to the ovarian phenotype expressed at 50 days of age. $\mathrm{A}$ and $\mathrm{B}$ represent Bonferroni's $\mathrm{Cl}$ and the overall mean $\mathrm{FSH}(\mathrm{A})$ and $\mathrm{AMH}(\mathrm{B})$ concentrations regardless of age during the first 9 weeks for both AFC groups. Asterisks indicate significant differences between groups: ANOVA $* P<0.05 ;{ }^{* *} P<0.0001$. Letters indicate significant differences among the weeks within the same group: ANOVA $P<0.0001$. Upper case letters: low AFC group; lower case letters: high AFC group. 

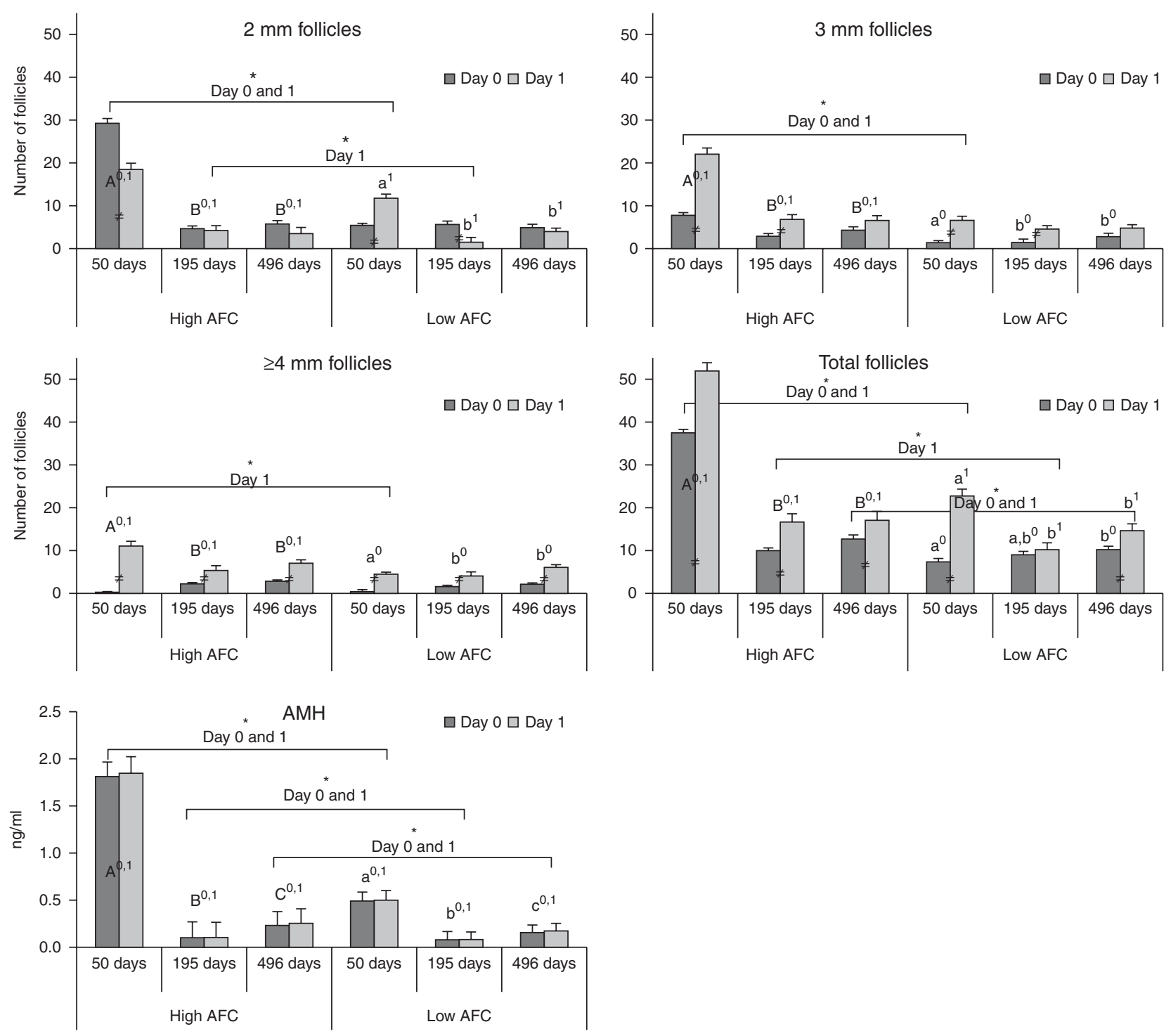

Figure 2 Follicle population and plasma AMH levels in ewe lambs assigned to high AFC ( $\geq 30$ follicles) or low AFC group ( $\leq 15$ follicles) according to the ovarian phenotype expressed at 50 days of age. Follicle population and AMH levels were determined both before (Day 0) and after (Day 1 ) FSH administration in the prepubertal (50 days of age; high AFC $n=24$, low AFC $n=24$ ), peripubertal (195 days of age; high AFC $n=24$, low AFC $n=24$ ), and postpubertal (496 days of age; high AFC $n=9$, low AFC $n=15$ ) period. Different letters indicate a statistical difference among different ages in the same group: GLM $P<0.0001$. Upper case letters: high AFC group; lower case letters: low AFC group. The symbol $\neq$ indicates differences in the number of follicles between Day 0 and Day 1 within the same group and the same age. The lines indicate differences in the number of follicles between the two experimental groups at the same age.

peripubertal period, to rise again, even if not reaching values comparable with those recorded in the youngest age, in the postpubertal period.

The response to ovarian stimulation changed over time (Fig. 3). The major response to ovarian stimulation with exogenous $\mathrm{FSH}$ was obtained at 50 days of age with a greater number of total new follicles in both groups $(21.92 \pm 4.08$ and $15.32 \pm 4.04$ for the high AFC group and the low AFC group respectively) than those obtained in subsequent EFORTs at 195 and 496 days of age $(7.17 \pm 1.06$ and $4.22 \pm 1.22$ in the high AFC group at 195 and 496 days of age, $0.79 \pm 0.74$ and $4.07 \pm 1.00$ in the low AFC group at 195 and 496 days of age). The number of new $3 \mathrm{~mm}$ and $\geq 4 \mathrm{~mm}$ follicles grown after FSH administration decreased at peripubertal and postpubertal age compared with the ones observed at an early prepubertal age. The decrease in the number of new $2 \mathrm{~mm}$ follicles was more marked in the high AFC group during the early prepubertal EFORT $(-8.08 \pm$ 1.91) than in the peripubertal $(-1.58 \pm 0.80)$ and postpubertal ones $(-2.22 \pm 1.27, P<0.01)$, but also the increase in the number of new follicles in larger categories was more marked during the early prepubertal EFORT. In the low AFC group there was an increase in 


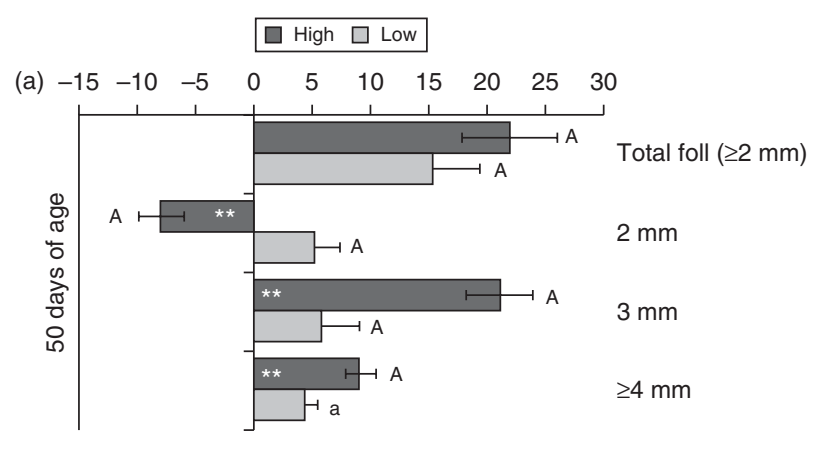

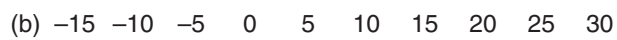

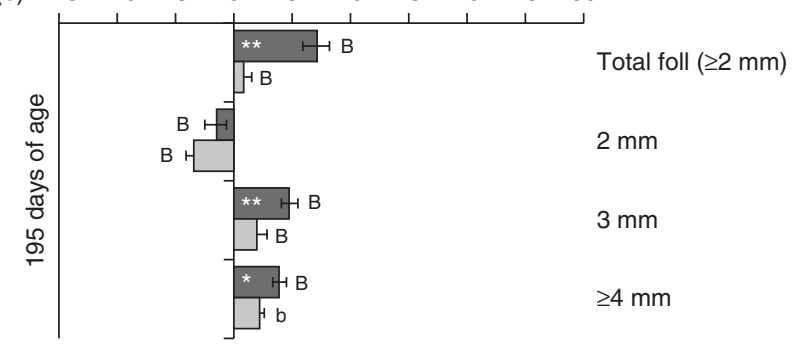

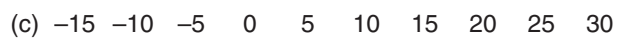

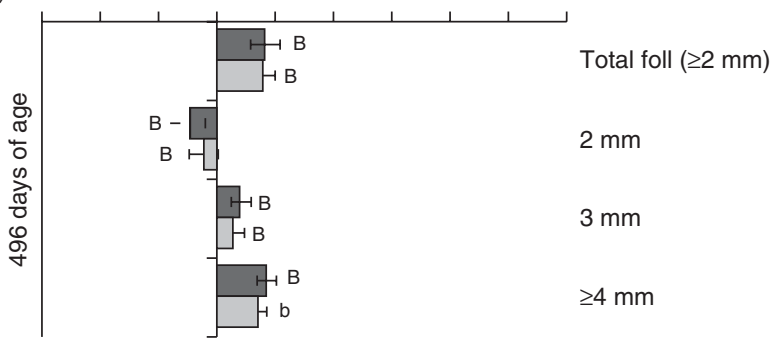

Figure 3 New follicles per follicular category $24 \mathrm{~h}$ after an ovarian stimulation test (EFORT) with FSH at 50 (a), 195 (b), and 496 (c) days of age in ewes classified according to their AFC (high $\geq 30$ follicles, low $\leq 15$ follicles) at an early prepubertal age (high AFC $n=24$, low AFC $n=24$ at 50 and 195 days of age; high AFC $n=9$, low AFC $n=15$ at 496 days of age). ${ }^{a, b, A, B}$ Indicate a statistical difference in the same follicular category in the same group among different EFORTs (GLM): $\mathrm{a} \neq \mathrm{b} P<0.05 ; \mathrm{A} \neq \mathrm{B} P<0.01$. *Indicate a statistical difference between groups in the same follicular category from the same EFORT: ${ }^{*} P<0.05$, $* * P<0.01$.

the number of new $2 \mathrm{~mm}$ follicles recruited after exogenous gonadotrophin stimulation at 50 days of age $(5.2 \pm 2.20)$ while, at 195 and 496 days of age there was a reduction in the number of new $2 \mathrm{~mm}$ follicles $(-3.46 \pm 0.62$ and $-1.07 \pm 1.19$ respectively, $P<0.01)$.

The GLMM of AMH selected for its best fit (based on the lowest $\mathrm{AIC}$ ) includes the group, the age, the random effect of the individual, and interaction between age and group as covariates. The proportion of deviance explained by this model was about $42 \%$. Results showed that the low AFC group is the one with the lowest estimated circulating AMH concentrations (estimated mean $=-483$, S.D. $=( \pm 100))$ with respect to the reference level (high AFC group). The age of the individual shows a negative relationship with estimated $\mathrm{AMH}$ (estimated mean $=-1.5$, S.D. $=( \pm 0.26)$ ), i.e. plasma
AMH concentrations decrease with age. The interaction between the age and the group show a positive relationship (estimated mean $=2.33$, s.D. $=( \pm 0.25)$ ) for the low AFC group, with respect to the reference level (high AFC group), i.e. the decrease in plasma $\mathrm{AMH}$ concentrations with age is more marked in the low AFC group compared with the high one.

\section{Study 3. Reproductive function in adulthood}

Regardless of their AFC in the early prepubertal period, 22 ewes from the total of 44 used in Study 3 became pregnant in the first breeding season, which represents a $50 \%$ pregnancy rate in the flock. Pregnancy rate in the first breeding season significantly differs between experimental groups $(65.2 \%$ for the high AFC group vs $33.3 \%$ for the low AFC group), with only seven of the 21 animals from the low AFC group becoming pregnant compared with 15 of the 23 ewes in the high AFC group $(P=0.03)$.

\section{Discussion}

The neonatal period is a critical stage in the process of sexual development and maturation. However, the significance of neonatal brain-pituitary-gonadal function has not been fully defined. The present study extends our knowledge on the linkage between $\mathrm{FSH}, \mathrm{AMH}$, and follicular dynamics during the postnatal period and on the effects of the stage of ovarian maturation during the early prepubertal period on subsequent reproductive function.

In the present study, by taking advantage of the experimental model developed in a previous work (Torres-Rovira et al. 2014), we found out that full term born ewe lambs with similar body weights show different patterns of postnatal pituitary activation. In particular, ewe lambs with high AFC at 50 days of age had significantly lower plasma FSH concentrations and significantly higher plasma AMH concentrations during the first 9 weeks of age compared with low AFC ewe lambs. These findings indicate a more advanced developmental stage of follicles in the group showing high AFC at 50 days of age. Moreover, they do not support the hypothesis that an increase in the postnatal FSH concentrations is needed to drive a greater follicular recruitment and stimulate the development of antral follicles during the first weeks after birth in sheep.

The interplay of $\mathrm{FSH}, \mathrm{AMH}$, and antral follicle development in the early prepubertal period has not been fully investigated to date. In a previous study, by using the same experimental model described here, we found that in 50 day-old ewe lambs, plasma $\mathrm{AMH}$ concentrations were positively related to AFC and to the number of large follicles grown after exogenous FSH administration (Torres-Rovira et al. 2014). The present 
study further confirms these previous findings. During the first 9 weeks of age ewe lambs with an ovarian phenotype characterized by high AFC at 50 days of age had low circulating $\mathrm{FSH}$ concentrations and high circulating $\mathrm{AMH}$ concentrations, which peaked at 5-6 weeks of age. On the contrary, a low AFC phenotype at 50 days of age is accompanied by significantly higher FSH concentrations, which peaked at 3-4 weeks of age, and with constantly low circulating AMH concentrations.

During the prepubertal phase, $\mathrm{AMH}$ concentrations have been found to be negatively correlated with FSH concentrations also in cattle (Monniaux et al. 2013). Considering that the maturation of the negative feedback loop mediated by ovarian hormones on the hypothalamo-pituitary complex is attained in utero (Rhind et al. 2001, Kotsampasi et al. 2009), the low FSH concentration found in the high AFC group are likely to be caused by the production of inhibin and estrogen by the high number of growing follicles (Mann et al. 1992). Similar plasma FSH concentration would be found in the low AFC only 7 weeks later. Thus, the hormonal milieu during the first 6 weeks of age differs significantly in ewe lambs from the two experimental groups, and it is likely that FSH does not drive the first wave of follicular development that occurs after birth in lambs.

Contrary to what happens in adults (Rico et al. 2009), and as reported in the present study, $\mathrm{AMH}$ concentrations in the early prepubertal period are not constant. In girls, AMH is barely detected at birth (Hudson et al. 1990) and later shows an increase during the postnatal period (Hagen et al. 2010, Kelsey et al. 2011). Likewise, it has been shown that is a marked increase in $\mathrm{AMH}$ between 1 and 3 months of age in cattle also (Monniaux et al. 2013). In prepubertal Rasa aragonesa ewe lambs the maximum plasma $\mathrm{AMH}$ concentration has been seen at different ages $(3,4.5$, or 6 months of age) in different ewe lambs (Lahoz et al. 2014). This finding may suggest the possibility of an increase in $\mathrm{AMH}$ concentrations later in life in the animals from the low AFC group. A recent study (Kuiri-Hänninen et al. 2011a,b) reported that in the postnatal period preterm girls had higher urinary $\mathrm{FSH}$ concentrations and lower serum $\mathrm{AMH}$ concentrations as compared with full term girls. In particular, authors evidenced that follicular development was delayed by $\sim 9$ weeks in preterm girls as compared with full-term girls, and that this delay was accompanied by an earlier and greater increase of serum $\mathrm{AMH}$ concentrations in full-term girls, indicating a more advanced developmental stage of follicles compared with preterm girls. These differences mirror what we observed in our two experimental groups, and suggest that full term ewe lambs are born with different stages of ovarian maturation, and that $\mathrm{AMH}$ concentrations in the postnatal period may represent a marker of ovarian maturation. Furthermore, in agreement to a more advanced stage of ovarian maturation in ewe lambs with a high AFC at 50 days, in a previous study of our research group we showed that oocytes collected from ovaries with the highest AFC proved to be the most competent to develop into a blastocyst after incorporation into an in vitro production system (Torres-Rovira et al. 2014). It is important to stress that, considering folliculogenesis time-line in sheep (McNatty et al. 1995), the difference in ovarian maturation stage and follicle differentiation observed between the groups studied are likely to be initiated during gestation. In this regard, the importance of ovarian maturation during fetal life has already been underlined (Kuiri-Hänninen et al. 2014).

The longitudinal experiment carried out in the present study demonstrated that, in ewe lambs, having a high or low AFC phenotype during the early prepubertal period has long-lasting effects on ovarian status and responsiveness to gonadotropin stimulation. A low AFC was indeed associated with constantly lower number of total follicles and plasma $\mathrm{AMH}$ concentrations up to the postpubertal period (496 days of age), even if differences in the response to FSH stimulation in terms of new follicles stimulated to grow tend to decrease with age. In addition, the statistical model developed evidenced that the decrease in plasma $\mathrm{AMH}$ concentrations with age is more marked in the low AFC group compared with the high one. In this regard, AFC and AMH are widely used to predict ovarian reserve and ovarian response to controlled stimulation with exogenous gonadotropins for assisted reproductive technologies (ARTs) treatments (La Marca et al. 2007, Aflatoonian et al. 2009, Fleming et al. 2015); moreover, a better prediction of ovarian responsiveness is achieved when using $\mathrm{AMH}, \mathrm{AFC}$, and age together (Brodin et al. 2015). Taken together, these results immediately suggest that high AFC and $\mathrm{AMH}$ concentrations in the early prepubertal period may represent a precocious marker of the ovarian reserve of a given individual, considering that the quantity and quality of non-growing follicles in the ovary is positively associated with the number of growing follicles, plasma AMH concentrations, and reproductive life-span (Monniaux et al. 2014). However, the results obtained in a previous study (Torres-Rovira et al. 2014) allow us to rule out differences in the size of the primordial follicle pool, often known as ovarian reserve, as the cause of the observed differences in AFC and $\mathrm{AMH}$ in the two experimental groups (Torres-Rovira et al. 2014). AFC and $\mathrm{AMH}$ concentrations in the early prepubertal period were indeed only predictive of the functional ovarian reserve (Gleicher et al. 2011), i.e. the number of growing follicles that can be recruited to grow by exogenous FSH. We speculated that the significant differences in AFC observed in prepubertal ewe lambs would simply reflect the slow increase in follicular activity (recruitment and development) that is required throughout this period, and that follicular recruitment and development are preparatory to the subsequent development of reproductive function. 
Some remarks on the post-pubertal EFORT results of our longitudinal study should be made. First, although the EFORT was performed during the anoestrus period for this breed and latitude, secondary follicular ways were not synchronized. Therefore, the response to FSH stimulation may slightly vary according to the phase of the follicular wave during which the gonadotropin stimulation occurs. However, AMH concentrations remain relatively constant along the whole cycle because there is a continuous growth of small follicles (La Marca et al. 2007) following a specific profile during the estrous cycle which occurs independently of the follicular waves (Rico et al. 2011); exhibit very little changes with season in seasonal breeding animals (goat, Monniaux et al. 2011), and arepositively correlated to ovarian response to exogenous stimulation (TorresRovira et al. 2014). Thus, we believe that the differences seen in the basal concentrations of $\mathrm{AMH}$ on Day 0 between the high and low AFC groups support the existence of the differences seen between both groups at 16.5 months in the EFORT response despite the nonsynchronization of the follicular wave. Secondly, we cannot completely rule out the possibility that our EFORT results at 16.5 months could somehow be influenced by the fact that only nonpregnant ewes at first breeding season, representing a smaller sample size and perhaps underlying not-detected reproductive problems, were used for this study.

With the longitudinal experiment we were able to show that a high AFC in the early prepubertal period is associated with consistently higher AMH concentrations and number of antral follicles, but also with higher pregnancy rates in the first breeding season. Some studies have associated higher AMH concentrations (Kamel et al. 2014, Sahmay et al. 2014) and AFC (Holte et al. 2011) with higher pregnancy rates in women undergoing reproductive treatments. However, longitudinal studies on plasma $\mathrm{AMH}$ at the prepubertal age and its implications in later reproductive life in girls and domestic animals are scarce.

A recent study reported that plasma $\mathrm{AMH}$ measured at 3 months in prepubertal ewe lambs was a marker for the number of ovarian follicles able to respond to gonadotropins at these early ages and was also positively correlated with fertility at their first mating (Lahoz et al. 2014). This result is in agreement with present findings, where ewe lambs with high AFC and AMH concentrations at 50 days of life showed higher pregnancy rates at the first breeding season, as compared with ewe lambs with low AFC and plasma AMH concentrations. The same research group reported in a subsequent study that the highest $\mathrm{AMH}$ value was found at different times $(3,4.5$, and 6 months of age) in different ewe lambs (Lahoz et al. 2014). The authors speculated that the large variations between animals observed in the pattern of plasma AMH concentrations before puberty may suggest that ovarian maturity occurs at an earlier age in some ewe lambs than in others. On the other hand, in contrast to present findings, plasma $\mathrm{AMH}$ concentration before puberty was not related to $\mathrm{AMH}$ concentration or the number of follicles grown after $\mathrm{FSH}$ treatment at the adult age (Lahoz et al. 2014).

In any case, the difference between our groups in the AFC and AMH points to a high individual variability in the occurrence of postnatal pituitary activation in sheep, as it occurs in human.

\section{Conclusion}

Our animal model helps to strengthen the knowledge of the perinatal period and its importance later in life, being a good model for the study of the 'minipuberty' occurrence and the delay in follicular development in girls and their possible implications in their later reproductive life. Results of the present study demonstrate that ewe lambs undergo different patterns of postnatal pituitary activation, and that a high AFC at 50 days of age indicates an advanced phase of ovarian maturation accompanied by high plasma $\mathrm{AMH}$ and low plasma FSH concentrations, although the mechanism driving the postnatal development of antral follicles remains unknown. In addition, in the high AFC group the more advanced stage of ovarian maturation in the early prepubertal period was accompanied by constantly higher $\mathrm{AMH}$ concentrations up to the postpubertal period, by a greater ovarian response to $\mathrm{FSH}$ stimulation, and by higher pregnancy rates at first mating, as compared with the low AFC group.

\section{Declaration of Interest}

The authors declare that there is no conflict of interest that could be perceived as prejudicing the impartiality of the research reported.

\section{Funding}

This study was supported by Regione Autonoma della Sardegna - MigliOviGen project. S Succu was supported by a Fondazione Banco di Sardegna grant.

\section{References}

Aflatoonian A, Oskouian H, Ahmadi S \& Oskouian L 2009 Prediction of high ovarian response to controlled ovarian hyperstimulation: anti-Mullerian hormone versus small antral follicle count $(2-6 \mathrm{~mm})$. Journal of Assisted Reproduction and Genetics 26 319-325. (doi:10.1007/s10815-009-9319-5)

Akaike H 1974 A new look at the statistical model identification. IEEE Transactions on Automatic Control $19716-723$.

Baarends WM, Uilenbroek JT, Kramer P, Hoogerbrugge JW, van Leeuwen EC, Themmen AP \& Grootegoed JA 1995 Anti-Mullerian hormone and anti-Mullerian hormone type II receptor messenger ribonucleic acid expression in rat ovaries during postnatal development, the estrous cycle, and gonadotropin-induced follicle growth. Endocrinology 136 4951-4962. (doi:10.1210/endo.136.11.7588229) 
Beck-Peccoz P, Padmanabhan V, Baggiani AM, Cortelazzi D, Buscaglia M, Medri G, Marconi AM, Pardi G \& Beitins IZ 1991 Maturation of hypothalamic-pituitary-gonadal function in normal human fetuses: circulating levels of gonadotropins, their common alpha-subunit and free testosterone, and discrepancy between immunological and biological activities of circulating follicle-stimulating hormone. Journal of Clinical Endocrinology and Metabolism 73 525-532. (doi:10.1210/jcem-73-3-525)

Brodin T, Hadziosmanovic N, Berglund L, Olovsson M \& Holte J 2015 Comparing four ovarian reserve markers - associations with ovarian response and live births after assisted reproduction. Acta Obstetricia et Gynecologica Scandinavica 94 1056-1063. (doi:10.1111/aogs.12710)

Campbell BK, Clinton M \& Webb R 2012 The role of anti-Mullerian hormone (AMH) during follicle development in a monovulatory species (sheep). Endocrinology 153 4533-4543. (doi:10.1210/en.2012-1158)

Carcangiu V, Mura MC, Vacca GM \& Bini PP 2005 Influence of body weight on reproductive activity in Sarda female lambs. Italian Journal of Animal Science 4 327-329.

Chellakooty M, Schmidt IM, Haavisto AM, Boisen KA, Damgaard IN, Mau C, Petersen JH, Juul A, Skakkebaek NE \& Main KM 2003 Inhibin A, inhibin B, follicle-stimulating hormone, luteinizing hormone, estradiol, and sex hormone-binding globulin levels in 473 healthy infant girls. Journal of Clinical Endocrinology and Metabolism 88 3515-3520. (doi:10.1210/jc.2002-021468)

Estienne A, Pierre A, di Clemente N, Picard JY, Jarrier P, Mansanet C, Monniaux D \& Fabre S 2015 Anti-Mullerian hormone regulation by the bone morphogenetic proteins in the sheep ovary: deciphering a direct regulatory pathway. Endocrinology 156 301-313. (doi:10.1210/en. 2014-1551)

Fanchin R, de Ziegler D, Olivennes F, Taieb J, Dzik A \& Frydman R 1994 Exogenous follicle stimulating hormone ovarian reserve test (EFORT): a simple and reliable screening test for detecting 'poor responders' in in-vitro fertilization. Human Reproduction 9 1607-1611.

Fanchin R, Schonauer LM, Righini C, Guibourdenche J, Frydman R \& Taieb J 2003 Serum anti-Mullerian hormone is more strongly related to ovarian follicular status than serum inhibin B, estradiol, FSH and LH on day 3. Human Reproduction 18 323-327. (doi:10.1093/humrep/deg042)

Fleming R, Seifer DB, Frattarelli JL \& Ruman J 2015 Assessing ovarian response: antral follicle count versus anti-Müllerian hormone. Reproductive Biomedicine Online 31 486-496. (doi:10.1016/j.rbmo. 2015.06.015)

Forest MG, De Peretti E \& Bertrand J 1980 Testicular and adrenal androgens and their binding to plasma proteins in the perinatal period: developmental patterns of plasma testosterone, 4-androstenedione, dehydroepiandrosterone and its sulfate in premature and small for date infants as compared with that of full-term infants. Journal of Steroid Biochemistry 12 25-36. (doi:10.1016/0022-4731(80)90247-2)

Gleicher N, Weghofer A \& Barad DH 2011 Defining ovarian reserve to better understand ovarian aging. Reproductive Biology and Endocrinology 9 23. (doi:10.1186/1477-7827-9-23)

Gluckman PD, Hanson MA, Cooper C \& Thornburg KL 2008 Effect of in utero and early-life conditions on adult health and disease. New England Journal of Medicine 359 61-73. (doi:10.1056/NEJMra0708473)

Gonzalez-Bulnes A, Santiago-Moreno J, Garcia-Lopez M, Gomez-Brunet A \& Lopez-Sebastian A 1994 Observacion del ovario en la oveja y eficacia en la deteccion de foliculos y cuerpos luteos mediante ecografia transrectal. Investigación agraria: Producción y sanidad animales 9 319-329.

Gruijters MJ, Visser JA, Durlinger AL \& Themmen AP 2003 Anti-Mullerian hormone and its role in ovarian function. Molecular and Cellular Endocrinology 211 85-90. (doi:10.1016/j.mce.2003.09.024)

Hagen CP, Aksglaede L, Sørensen K, Main KM, Boas M, Cleemann L, Holm K, Gravholt CH, Andersson AM, Pedersen AT et al. 2010 Serum levels of anti-Müllerian hormone as a marker of ovarian function in 926 healthy females from birth to adulthood and in 172 turner syndrome patients. Journal of Clinical Endocrinology and Metabolism 95 5003-5010. (doi:10.1210/jc.2010-0930)

Hernandez-Medrano JH, Campbell BK \& Webb R 2012 Nutritional influences on folliculogenesis. Reproduction in Domestic Animals $\mathbf{4 7}$ 274-282. (doi:10.1111/j.1439-0531.2012.02086.x)

Holte J, Brodin T, Berglund L, Hadziosmanovic N, Olovsson M \& Bergh T 2011 Antral follicle counts are strongly associated with live-birth rates after assisted reproduction, with superior treatment outcome in women with polycystic ovaries. Fertility and Sterility 96 594-599. (doi:10.1016/j. fertnstert.2011.06.071)

Hudson PL, Dougas I, Donahoe PK, Cate RL, Epstein J, Pepinsky RB \& MacLaughlin DT 1990 An immunoassay to detect human Mullerian inhibiting substance in males and females during normal development. Journal of Clinical Endocrinology and Metabolism 70 16-22. (doi:10.1210/jcem-70-1-16)

Jayaprakasan K, Campbell BK, Clewes JS, Johnson IR \& Raine-Fenning NJ 2008 Three-dimensional ultrasound improves the interobserver reliability of antral follicle counts and facilitates increased clinical work flow. Ultrasound Obstetrics and Gynecology 31 439-444. (doi:10.1002/uog.5301)

Jeppesen JV, Anderson RA, Kelsey TW, Christiansen SL, Kristensen SG, Jayaprakasan K, Raine-Fenning N, Campbell BK \& Yding Andersen C 2013 Which follicles make the most anti-Mullerian hormone in humans? Evidence for an abrupt decline in $\mathrm{AMH}$ production at the time of follicle selection Molecular Human Reproduction 19 519-527. (doi:10.1093/ molehr/gat024)

Kamel HM, Amin AH \& Al-Adawy AR 2014 Basal serum anti-Mullerian hormone $(\mathrm{AMH})$ is a promising test in prediction of occurrence of pregnancy rate in infertile women undergoing ICSI cycles. Clinical Laboratory 60 1717-1723. (doi:10.7754/Clin.Lab.2014.131015)

Kelsey TW, Wright P, Nelson SM, Anderson RA \& Wallace WH 2011 A validated model of serum anti-Mullerian hormone from conception to menopause. PLOS ONE 6 e22024. (doi:10.1371/journal. pone.0022024)

Kotsampasi B, Chadio S, Papadomichelakis G, Deligeorgis S, Kalogiannis D, Menegatos I \& Zervas G 2009 Effects of maternal undernutrition on the hypothalamic-pituitary-gonadal axis function in female sheep offspring. Reproduction in Domestic Animals 44 677-684. (doi:10.1111/j.1439-0531.2007.01046.x)

Kuiri-Hänninen T, Seuri R, Tyrvainen E, Turpeinen $U$, Hamalainen $E$, Stenman UH, Dunkel L \& Sankilampi U 2011 a Increased activity of the hypothalamic-pituitary-testicular axis in infancy results in increased androgen action in premature boys. Journal of Clinical Endocrinology and Metabolism 96 98-105. (doi:10.1210/jc.2010-1359)

Kuiri-Hänninen T, Kallio S, Seuri R, Tyrväinen E, Liakka A, Tapanainen J, Sankilampi U \& Dunkel L 2011b Postnatal developmental changes in the pituitary-ovarian axis in preterm and term infant girls. Journal of Clinical Endocrinology and Metabolism 11 3432-3439. (doi:10.1210/jc. 2011-1502)

Kuiri-Hänninen T, Sankilampi U \& Dunkel L 2014 Activation of the hypothalamic-pituitary-gonadal axis in infancy: minipuberty. Hormone Research in Paediatrics 82 73-80. (doi:10.1159/000362414)

Kwee J, Schats R, McDonnell J, Schoemaker J \& Lambalk CB 2006 The clomiphene citrate challenge test versus the exogenous folliclestimulating hormone ovarian reserve test as a single test for identification of low responders and hyperresponders to in vitro fertilization. Fertility and Sterility 85 1714-1722. (doi:10.1016/j.fertnstert.2005.11.053)

Lahoz B, Alabart JL, Cocero MJ, Monniaux D, Echegoyen E, Sanchez P \& Folch J 2014 Anti-Mullerian hormone concentration in sheep and its dependence of age and independence of BMP15 genotype: an endocrine predictor to select the best donors for embryo biotechnologies. Theriogenology 81 347-357. (doi:10.1016/j.theriogenology.2013. 09.033)

Lahoz B, Alabart JL, Monniaux D, Mermillod P \& Folch J 2012 AntiMüllerian hormone plasma concentration in prepubertal ewe lambs as a predictor of their fertility at a young age. BMC Veterinary Research 8 1-9. (doi:10.1186/1746-6148-8-118)

La Marca A, Giulini S, Tirelli A, Bertucci E, Marsella T, Xella S \& Volpe A 2007 Anti-Mullerian hormone measurement on any day of the menstrual cycle strongly predicts ovarian response in assisted reproductive technology. Human Reproduction 22 766-771. (doi:10.1093/humrep/del421)

Lee MM 2003 Reproductive hormones in infant girls - a harbinger of adult reproductive function? Journal of Clinical Endocrinology and Metabolism 88 3513-3514. (doi:10.1210/jc.2003-031038)

Mahdi D \& Khallili K 2008 Relationship between follicle growth and circulating gonadotrophin levels during postnatal development of sheep. Animal Reproduction Science 1-2 100-112. (doi:10.1016/j.anireprosci. 2007.04.008) 
Mann GE, Campbell BK, McNeilly AS \& Baird DT 1992 The role of inhibin and oestradiol in the control of FSH secretion in the sheep. Journal of Endocrinology 133 381-391. (doi:10.1677/joe.0.1330381)

McGee EA, Smith R, Spears N, Nachtigal MW, Ingraham H \& Hsueh AJ 2001 Mullerian inhibitory substance induces growth of rat preantral ovarian follicles. Biology of Reproduction 64 293-298. (doi:10.1095/ biolreprod64.1.293)

McNatty KP, Smith P, Hudson NL, Heath DA, Tisdall DJ, O WS \& BrawTal R 1995 Development of the sheep ovary during fetal and early neonatal life and the effect of fecundity genes. Journal of Reproduction and Fertility Supplement 49 123-135.

McNatty KP, Isaacs KL, Gentle L, Berry L, Hudson NL, Young W \& McLeod BJ 1998 Bioactive and immunoreactive FSH concentrations in ewe and ram lambs over the first year of life. Animal Reproduction Science 2 155-166. (doi:10.1016/S0378-4320(98)00055-4)

Monniaux D, Baril G, Laine AL, Jarrier P, Poulin N, Cognie J \& Fabre S 2011 Anti-Mullerian hormone as a predictive endocrine marker for embryo production in the goat. Reproduction 142 845-854. (doi:10.1530/REP11-0211)

Monniaux D, Drouilhet L, Rico C, Estienne A, Jarrier P, Touze JL, Sapa J, Phocas F, Dupont J, Dalbies-Tran R et al. 2013 Regulation of antiMullerian hormone production in domestic animals. Reproduction, Fertility and Development 25 1-16. (doi:10.1071/RD12270)

Monniaux D, Clement F, Dalbies-Tran R, Estienne A, Fabre S, Mansanet C \& Monget P 2014 The ovarian reserve of primordial follicles and the dynamic reserve of antral growing follicles: what is the link? Biology of Reproduction 90 85. (doi:10.1095/biolreprod.113.117077)

Pellatt L, Rice S, Dilaver N, Heshri A, Galea R, Brincat M, Brown K, Simpson ER \& Mason HD 2011 Anti-Müllerian hormone reduces follicle sensitivity to follicle-stimulating hormone in human granulosa cells. Fertility and Sterility 96 1246-1251. (doi:10.1016/j.fertnstert.2011.08.015)

Rawlings NC, Evans ACO, Honaramooz A \& Bartlewski PM 2003 Antral follicle growth and endocrine changes in prepubertal cattle, sheep and goats. Animal Reproduction Science 3-4 259-270. (doi:10.1016/S03784320(03)00094-0)

R Development Core Team 2014 R: A Language and Environment for Statistical Computing. Vienna, Austria : the R Foundation for Statistical Computing. Available online at http://www.R-project.org/

Rhind SM, Rae MT \& Brooks AN 2001 Effects of nutrition and environmental factors on the fetal programming of the reproductive axis. Reproduction 122 205-214. (doi:10.1530/rep.0.1220205)

Rico C, Fabre S, Medigue C, di Clemente N, Clement F, Bontoux M, Touze JL, Dupont M, Briant E, Remy B et al. 2009 Anti-Mullerian hormone is an endocrine marker of ovarian gonadotropin-responsive. Biology of Reproduction 80 50-59. (doi:10.1095/biolreprod.108.072157)

Rico C, Médigue C, Fabre S, Jarrier P, Bontoux M, Clément F \& Monniaux D 2011 Regulation of anti-müllerian hormone production in the cow: A multiscale study at endocrine, ovarian, follicular and granulosa cell levels. Biology of Reproduction 84 560-571. (doi:10.1095/biolreprod. 110.088187)
Rico CA, Drouilhet LA, Salvetti PB, Dalbiès-Tran RA, Jarrier PA, Touzé J-LA, Pillet EB, Ponsart CB, Fabre SA \& Monniaux D 2012 Determination of anti-Müllerian hormone concentrations in blood as a tool to select Holstein donor cows for embryo production: from the laboratory to the farm. Reproduction, Fertility and Development 24 932-944. (doi:10.1071/RD11290)

Sahmay S, Oncul M, Tuten A, Tok A, Acıkgoz AS \& Cepni I 2014 Anti-müllerian hormone levels as a predictor of the pregnancy rate in women of advanced reproductive age. Journal of Assisted Reproduction and Genetics 31 1469-1474. (doi:10.1007/s10815-014-0324-y)

Savoie S, Forest MG, Bourel B, Saez JM, Collu R, Bertrand J \& Ducharme JR 1979 Perinatal activity of the hypothalamic pituitary gonadal axis in the lamb. I. Circulating levels of $\mathrm{LH}, \mathrm{FSH}$, prolactin and testosterone and in vivo response to hCG in the first two months of life. Biology of Reproduction 21 1051-1056. (doi:10.1095/biolreprod21.5.1051)

Schmidt H \& Schwarz HP 2000 Serum concentrations of LH and FSH in the healthy newborn. European Journal of Endocrinology 143 213-215. (doi:10.1530/eje.0.1430213)

Silberstein T, MacLaughlin DT, Shai I, Trimarchi JR, Lambert-Messerlian G, Seifer DB, Keefe DL \& Blazar AS 2006 Mullerian inhibiting substance levels at the time of HCG administration in IVF. Human Reproduction 21 159-163. (doi:10.1093/humrep/dei270)

Sloboda DM, Howie GJ, Pleasants A, Gluckman PD \& Vickers MH 2009 Pre- and postnatal nutritional histories influence reproductive maturation and ovarian function in the rat. PLOS ONE 4 e6744. (doi:10.1371/ journal.pone.0006744)

Torres-Rovira L, Gonzalez-Bulnes A, Succu S, Spezzigu A, Manca ME, Leoni GG, Sanna M, Pirino S, Gallus M, Naitana S et al. 2014 Predictive value of antral follicle count and anti-Müllerian hormone for follicle and oocyte developmental competence during the early prepubertal period in a sheep model. Reproduction, Fertility and Development 8 1094-1106. (doi:10.1071/RD13190)

Weenen C, Laven JS, Von Bergh AR, Cranfield M, Groome NP, Visser JA, Kramer P, Fauser BC \& Themmen AP 2004 Anti-Mullerian hormone expression pattern in the human ovary: potential implications for initial and cyclic follicle recruitment. Molecular Human Reproduction 10 77-83. (doi:10.1093/molehr/gah015)

Zambrano E, Guzman C, Rodriguez-Gonzalez GL, Durand-Carbajal M \& Nathanielsz PW 2014 Fetal programming of sexual development and reproductive function. Molecular and Cellular Endocrinology $\mathbf{3 8 2}$ 538-549. (doi:10.1016/j.mce.2013.09.008)

Received 10 July 2015

First decision 3 August 2015

Revised manuscript received 28 October 2015

Accepted 30 November 2015 